\title{
Deep Neuromuscular Blockade Improves Laparoscopic Surgical Conditions: A Randomized, Controlled Study
}

\author{
Jacob Rosenberg · W. Joseph Herring • Manfred Blobner • \\ Jan P. Mulier • Niels Rahe-Meyer · Tiffany Woo · Michael K. Li • \\ Peter Grobara • Christopher A. Assaid · Hein Fennema • \\ Armin Szegedi
}

Received: January 4, 2017 / Published online: March 1, 2017

(c) The Author(s) 2017. This article is published with open access at Springerlink.com

\section{ABSTRACT}

Introduction: Sustained deep neuromuscular blockade (NMB) during laparoscopic surgery may facilitate optimal surgical conditions. This exploratory study assessed whether deep NMB improves surgical conditions and, in doing so, allows use of lower insufflation pressures during laparoscopic cholecystectomy. We further assessed whether use of low insufflation pressure improves patient pain scores after surgery. Methods: This randomized, controlled, blinded study (NCT01728584) compared use of deep

Enhanced content To view enhanced content for this article go to http://www.medengine.com/Redeem/6D8 7F060476B506A.

Electronic supplementary material The online version of this article (doi:10.1007/s12325-017-0495-x) contains supplementary material, which is available to authorized users.

J. Rosenberg

Gastrointestinal Unit, Surgical Section, Herlev

Hospital, University of Copenhagen, Herlev,

Denmark

W. J. Herring · T. Woo · M. K. Li · C. A. Assaid .

A. Szegedi

Merck, Kenilworth, NJ, USA

M. Blobner $(\square)$

Klinik für Anaesthesiologie der Technischen

Universität, Munich, Germany

e-mail: m.blobner@tum.de
(1-2 post-tetanic-counts) or moderate (train-of-four ratio $10 \%) \mathrm{NMB}$, and lower $(8 \mathrm{mmHg})$ or higher $(12 \mathrm{mmHg}$; 'standard') insufflation pressure in a $2 \times 2$ factorial design. Primary endpoint was surgeon's overall satisfaction with surgical conditions, rated at end of surgery using an 11-point numerical scale. Post-operative pain scores were also evaluated. Data were analyzed using analysis of covariance.

Results: Of 127 randomized patients, 120 had evaluable data for the primary endpoint. Surgeon's score of overall satisfaction with surgical conditions was significantly higher with deep versus moderate $\mathrm{NMB}$ indicated by a leastsquare mean difference of 1.1 points (95\% confidence interval $0.1-2.0 ; P=0.026$ ). Furthermore, strong evidence of an effect was observed for standard versus low pressure: least-square mean difference of 3.0 points $(95 \%$ confidence interval 2.1-4.0; $P<0.001$ ). No significant difference was observed in average pain scores within $24 \mathrm{~h}$ post-surgery for low versus

J. P. Mulier

AZ Sint Jan Brugge-Oostende, Brugge, Belgium

N. Rahe-Meyer

Franziskus Hospital Bielefeld, Hannover Medical

School, Bielefeld, Germany

P. Grobara · H. Fennema

MSD, Oss, The Netherlands 
standard pressure $[0.17$ (95\% confidence interval -0.67 to +0.33$) ; P=0.494]$.

Conclusions: Although associated with significantly improved surgical conditions, deep NMB alone was insufficient to promote use of low insufflation pressure during laparoscopic cholecystectomy. Furthermore, low insufflation pressure did not result in reduced pain, compared with standard pressure.

Clinical Trial Registration: ClinicalTrials.gov identifier, NCT01728584.

Funding: Merck Sharp and Dohme Corp., a subsidiary of Merck \& Co., Inc., Kenilworth, NJ, USA.

Keywords: Deep neuromuscular blockade; Insufflation pressure; Laparoscopy; Pain; Surgical conditions

\section{INTRODUCTION}

Laparoscopic procedures are becoming increasingly frequent in clinical practice due to a number of benefits versus open surgery, including faster recovery, shorter hospitalization times, less post-operative pain, and an improved cosmetic result [1]. Creating a pneumoperitoneum with insufflation of $\mathrm{CO}_{2}$ at approximately $12-15 \mathrm{mmHg}$ is routine in laparoscopic procedures [2] to provide an acceptable view of the surgical field. However, the raising of intra-abdominal pressure results in a variety of physiological changes [3], and has been associated with pain [4]. Previous studies have found use of lower $\mathrm{CO}_{2}$ insufflation pressures to be advantageous in terms of pain levels experienced post-operatively [4-6], although these findings have not been consistent across other studies [7].

Neuromuscular blocking agents (NMBAs) are used adjunctively to anesthesia to facilitate tracheal intubation, relax the abdominal muscles and reduce patient movements during surgery. Use of deeper levels of neuromuscular blockade (NMB) can improve surgical conditions in laparoscopic procedures [8], with potential benefits of sustained NMB throughout the whole procedure including an enhanced visual field, as well as increased ease of surgical access and manipulation and facilitation of closure. A limitation of the use of deep NMB in the past was the lack of reversal agent that would allow the anesthesiologist to reliably, predictably and rapidly reverse a deep NMB at any given time during surgery. However, sugammadex has now been approved in more than 80 countries as a novel compound proven to reverse deep levels of $\mathrm{NMB}$ rapidly and safely.

The relationship between insufflation pressure and depth of NMB has not been systematically studied. Therefore, the present study was intended as a first step to investigate the potential of a combination of deep NMB with a lower level of insufflation pressure to provide a potential two-fold benefit in the setting of endoscopic abdominal surgery: optimal surgical conditions for the surgeon and reduced post-operative pain for the patient. The primary objective of the study was to assess the benefit of deep NMB on surgical conditions when compared with moderate $\mathrm{NMB}$, assessed in the context of low and standard insufflation pressure during laparoscopic cholecystectomy. A secondary objective was to assess whether the use of low insufflation pressure improves the patient's overall pain score within $24 \mathrm{~h}$ after surgery.

\section{METHODS}

\section{Study Design and Patients}

This was a randomized, controlled, parallel-group, blinded study (Clinicaltrials.gov identifier NCT01728584; Sponsor Protocol Number P076), conducted at eleven centers (two in Austria, two in Finland, five in Germany, one in Italy and one in the United Kingdom) from January 2013 to April 2014. The study was conducted in accordance with principles of Good Clinical Practice and with the Helsinki Declaration of 1964, as revised in 2013, and was approved by the appropriate institutional review board/ethics committees. Informed consent was obtained from all patients for being included in the study. The study is reported according to the CONSORT statement. 
Included patients were adults of American Society of Anesthesiologists Class 1-3, with body mass index (BMI) $<35 \mathrm{~kg} / \mathrm{m}^{2}$, scheduled to undergo laparoscopic cholecystectomy under general anesthesia and rocuronium-induced NMB. All patients were required to provide written, informed consent. Patients were excluded if they had suspected difficult intubation, a history of previous abdominal surgery, a history of substance abuse or dependence, evidence of acute cholecystitis, renal or liver dysfunction, a history of a chronic pain condition, known intolerance to any drug used or planned to use for anesthesia, or if they had participated in any other clinical trial within 30 days. Female patients were also excluded if they were pregnant or were planning to become pregnant within the study period or had given birth to one or more children within the last year.

The study examined two depths of blockade and two insufflation pressures in a $2 \times 2$ factorial design: moderate blockade [train-of-four (TOF) ratio of $10 \%$; range TOF count $2-3$ to TOF ratio of $20 \%$, deep blockade [1-2 post-tetanic counts (PTC); range 1-5 PTC], standard pressure (set as $12 \mathrm{mmHg}$ ), and low pressure $(8 \mathrm{mmHg}$ ). This design allows for inferential statistical analysis of the effect of depth of blockade as well as insufflation pressure.

Using an interactive voice response system, patients were randomized centrally in a $1: 1: 1: 1$ ratio to one of each of the four combinations (Fig. 1) stratified by the surgeon/surgical team (i.e., surgeon with anesthesiologist) at the site

Randomized $(n=127)$
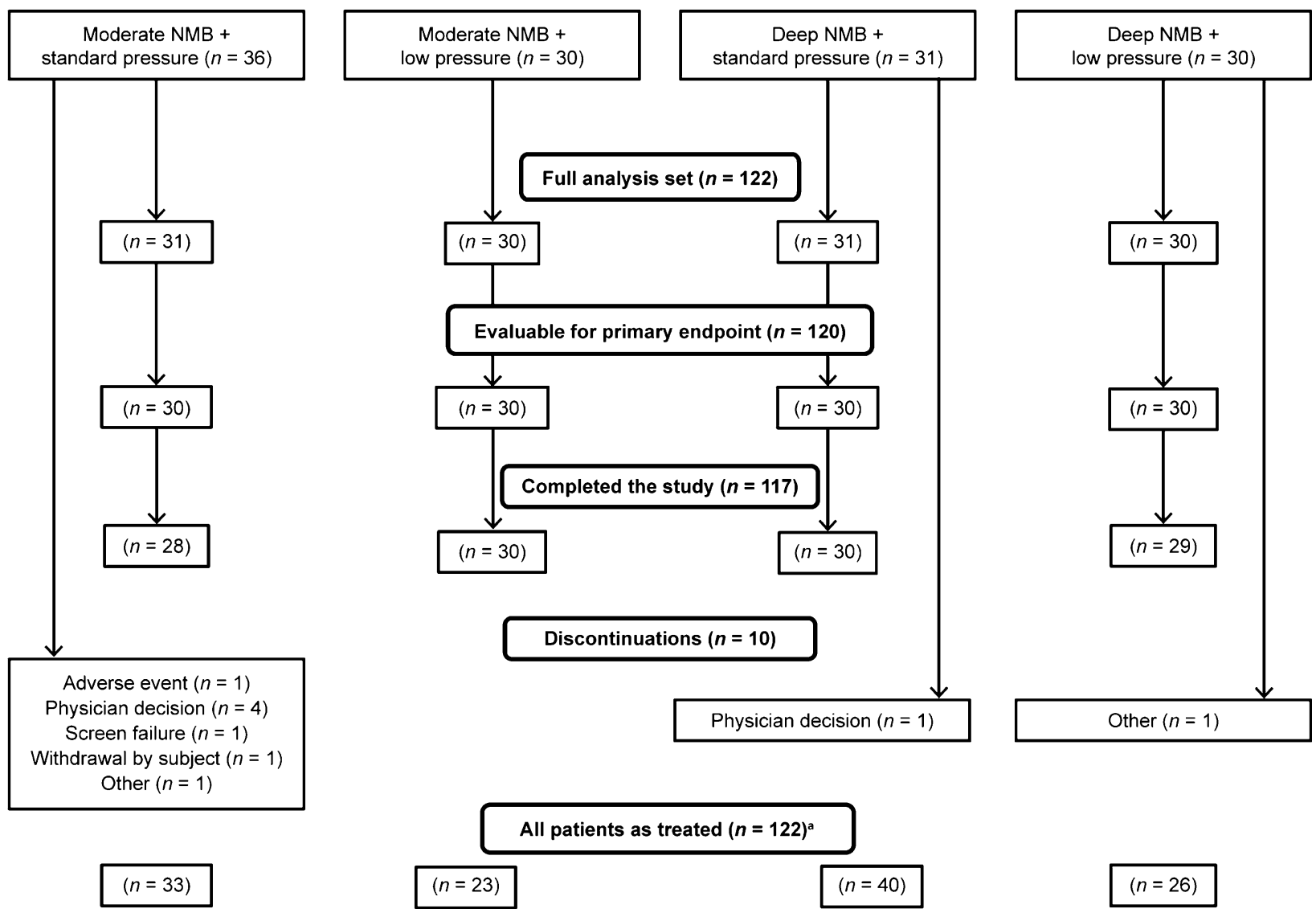

Fig. 1 Patient flow-through study; $N M B$ neuromuscular blockade. ${ }^{a}$ Surgeons were allowed to change surgical conditions as needed; therefore, a patient's final treatment may be different from their randomized assignment 
level. Any patients that prematurely discontinued from the study and had missing outcome for the primary/key secondary endpoint(s) were replaced by a patient assigned to the same surgeon with the same treatment assignment.

\section{Study Procedures}

\section{Anesthesia and NMB Regimen}

All patients received a standard regimen for general anesthesia using total intravenous anesthesia. Propofol $(2.5 \mathrm{mg} / \mathrm{kg})$ and remifentanil $(1 \mu \mathrm{g} / \mathrm{kg})$ were given for anesthesia induction. Anesthesia was maintained with a propofol infusion, titrated to maintain a bispectral index of 40-50 throughout surgery with a starting infusion rate of $6-12 \mathrm{mg} / \mathrm{kg} / \mathrm{h}$ $(100-200 \mu \mathrm{g} / \mathrm{kg} / \mathrm{min})$. Remifentanil infusion was adapted $(0.25 \mu \mathrm{g} / \mathrm{kg} / \mathrm{min})$ as required by the anesthesiologist based on the hemodynamic reactions. An intravenous bolus dose of $0.45 \mathrm{mg} / \mathrm{kg}$ rocuronium was given for intubation, with additional bolus doses or rocuronium infusion used to maintain $\mathrm{NMB}$ at the required depth. NMB was monitored using the TOFWatch $^{\circledR}$ SX (Organon Ireland, a subsidiary of Merck, Swords, Co. Dublin, Ireland). Moderate $\mathrm{NMB}$ was maintained at a targeted TOF ratio of $10 \%$ (range TOF count of $2-3$ to a TOF ratio of $20 \%$ ). Deep NMB was maintained at a targeted depth of 1-2 PTC (range 1-5 PTC).

Once the target depth of NMB was reached, $\mathrm{CO}_{2}$ insufflation was initiated. The pneumoperitoneum was continuously controlled by the anesthesiologist, with the surgical team blinded to the applied insufflation pressure. If surgical conditions were deemed unacceptable with the assigned treatment, rescue interventions could be performed. For patients randomized to moderate $\mathrm{NMB}$, the depth of NMB could be increased to 1-2 PTCs. Further, the pneumoperitoneum pressure could be increased by $4 \mathrm{mmHg}$. For patients already under deep $\mathrm{NMB}$, pneumoperitoneum pressure could be increased by $4 \mathrm{mmHg}$.

The surgical conditions assessment score was obtained from the surgeon shortly after surgery. Patients who underwent rescue intervention were assigned the worst possible surgical conditions assessment score of 0 .

After the last dose of rocuronium, a single intravenous bolus dose of sugammadex 2 or $4 \mathrm{mg} / \mathrm{kg}$ was administered within $10 \mathrm{~s}$ into a fast-running intravenous infusion for reversal of moderate and deep NMB, respectively.

\section{Pain Management Regimen}

At the end of the remifentanil infusion and prior to extubation, a bolus dose of $8 \mathrm{mg}$ morphine was administered. Patients received morphine via patient-controlled analgesia for $2 \mathrm{~h}$ while in the post-anesthesia care unit (PACU). After discharge from the PACU, patients were provided with oral pain medication of $4 \times 400 \mathrm{mg}$ ibuprofen and $4 \times 1000 \mathrm{mg}$ paracetamol until day 5 . Additional pain medication could be taken as needed by the patient, with use of all pain medications systematically recorded until day 8 .

\section{Blinding}

The patient, surgeon, and safety assessors were all blinded to treatment. The anesthesiologists were not blinded as they needed to control the depth of NMB and record the dose and time of administration of all medications, insufflation pressures, and changes to the insufflation pressure or NMB as requested by the surgeon. The surgeon was also blinded to the type of rescue intervention.

\section{Assessments}

Surgeons rated several parameters of surgical conditions at end of surgery (primary endpoint) using an 11-point (discrete) numerical scale from 0 (poor, needs intervention) to 10 (excellent). The pre-specified primary endpoint in this study was the surgeon-rated overall satisfaction at end of surgery. Additional secondary endpoints included specific aspects of the surgical conditions, surgeon's satisfaction with surgical field visibility, surgeon's overall rating of adequacy of muscle relaxation and insufflation pressure, the number of patient movements interfering with surgical conditions, and the 
number of rescue actions performed during surgery to improve surgical conditions.

After completion of surgery, patients recorded their pain intensity at rest and when provoked by transition from lying to sitting position, and post-operative shoulder pain at the time of the assessment, using a numerical scale from 0 (no pain) to 10 (severe pain). Patients rated their pain score at 1, 2, 4, 24 and $48 \mathrm{~h}$, post-operatively as well as daily in the morning on days 3-8. The key secondary endpoint was the pain score within $24 \mathrm{~h}$ (average of the pain assessments at 1, 2, 4 and $24 \mathrm{~h}$ ). The amount of pain medication received post-operatively was assessed as an exploratory endpoint.

Safety was assessed via monitoring of adverse events (AEs) and vital signs. Incidences of nausea and vomiting were recorded, as were analgesic and anti-emetic medication consumption, until day 8. Clinical evidence of residual NMB or recurrence of NMB (e.g., significant change in respiratory rate or oxygen saturation level) was assessed from time of reversal of NMB with sugammadex until the patient was ready for discharge from the PACU.

\section{Statistical Analysis}

The primary hypothesis was that use of sustained deep NMB improves the surgeon's overall satisfaction with surgical conditions, compared with moderate NMB. The key secondary hypothesis was that use of low insufflation pressure improves the patient overall pain score within $24 \mathrm{~h}$.

A sample size of 30 patients per each of the four treatment groups was determined to have a power of more than $80 \%$ to analyze the primary hypothesis at an overall two-sided 5\% alphalevel, if the underlying treatment difference in the mean surgical conditions score was at least $52 \%$ of the standard deviation [9]. The sample size was also determined to provide $80 \%$ power to analyze the key secondary hypothesis.

The efficacy analyses were performed on the full analysis set (FAS), defined as all randomized patients who received rocuronium-induced NMB and pneumoperitoneum, according to randomization, and who did not convert to open surgery before the start of application of NMB and/or insufflation pressure. Analysis of covariance (ANCOVA) was performed, using factors for depth of NMB, level of insufflation pressure, surgeon; with BMI added for the primary efficacy analysis and gender added for the key secondary analysis. ANCOVA was performed using SAS 9.1 (SAS Institute, Cary, NC, USA). A hierarchical approach was taken to control for multiple testing: the primary contrast for the primary endpoint was tested at a level of $5 \%$. Only if the associated null hypothesis could be rejected at that level, the contrast of interest for the key secondary endpoint was tested at a level of $5 \%$. A rescue change in the level of insufflation pressure and/ or depth of $\mathrm{NMB}$ due to unacceptable surgical conditions was permitted per the protocol. According to the pre-defined analysis plan, the score for any patients for whom rescue was required was to be imputed as the worst possible assessment score of 0 .

The interaction between the two treatment factors (depth of NMB and insufflation pressure) was investigated in a sensitivity analysis, by adding an interaction term to the ANCOVA model. In the case of deviation from normality, a stratified Wilcoxon (non-parametric) test was also performed as a supportive analysis. This analysis compared the two levels of one treatment factor [providing Hodges-Lehmann estimates for the median difference and associated 95\% confidence interval (CI)] while using the two levels of the other treatment factor as strata. For the primary parameter, the main comparison was deep $\mathrm{NMB}$ versus standard $\mathrm{NMB}$, and for the key secondary parameter (average pain score), low pressure versus standard pressure. The sensitivity analyses were interpreted in an exploratory sense, with unadjusted $P$ values $<0.05$ considered nominally significant.

All safety analyses were performed on the all-patients-as-treated (APaT) set, defined as all randomized patients who received rocuronium-induced $\mathrm{NMB}$ or pneumoperitoneum, according to actual treatment conditions (depth of NMB and level of insufflation pressure).

Amount of pain medication received post-operatively was analyzed via ANCOVA. 


\section{RESULTS}

Of 127 randomized patients, 122 received treatment with rocuronium and pneumoperitoneum according to randomization, and were included in the FAS population for efficacy analyses. Two patients discontinued prematurely and were not evaluable; therefore 120 had evaluable data for the primary endpoint (Fig. 1). There was a greater proportion of male $(62.2 \%)$ versus female $(37.8 \%)$ patients. Patient characteristics are shown in Table 1.

In total, 122 patients were included in the APaT population for safety analyses; 12 patients (moderate blockade/low pressure, $n=7$; deep blockade/low pressure, $n=5$ ) had a permitted rescue change in level of insufflation pressure and/or depth of NMB after start of surgery due to unacceptable surgical conditions. No patient in the standard pressure groups required rescue intervention.

\section{Efficacy}

The surgeon's score of overall satisfaction with surgical conditions was significantly better with deep versus moderate NMB by 1.1 points on the 10-point scale (95\% CI $0.1-2.0 ; \quad P=0.026)$ (Table 3; Fig. 2). Improvement in surgical conditions was also observed with standard versus low pressure by 3.0 points (95\% CI 2.1-4.0; unadjusted $P<0.001$; Fig. 2). This analysis was not associated with a pre-specified hypothesis, but was performed for completeness of the assessment of the effect of both factors in the factorial design. The breakdown of surgical scores and ANCOVA results for the combined NMB and pressure groups are shown in Table 2.

The pre-specified sensitivity analysis of the primary endpoint, using the actual assessment score for surgical conditions before any rescue intervention, supported the results of the primary approach (Table 3). Additionally, a

Table 1 Patient baseline characteristics (all-patients-as-randomized set)

\begin{tabular}{|c|c|c|c|c|c|}
\hline$n(\%)$ & $\begin{array}{l}\text { Moderate } \\
\text { NMB }+ \text { moderate } \\
\text { pressure }(n=36)\end{array}$ & $\begin{array}{l}\text { Moderate } \\
\text { NMB + low } \\
\text { pressure }(n=30)\end{array}$ & $\begin{array}{l}\text { Deep } \\
\text { NMB }+ \text { moderate } \\
\text { pressure }(n=31)\end{array}$ & $\begin{array}{l}\text { Deep } \\
\text { NMB + low } \\
\text { pressure }(n=30)\end{array}$ & $\begin{array}{l}\text { Total } \\
(n=127)\end{array}$ \\
\hline \multicolumn{6}{|l|}{ Gender } \\
\hline Male & $21(58.3)$ & $19(63.3)$ & $18(58.1)$ & $21(70.0)$ & $79(62.2)$ \\
\hline Female & $15(41.7)$ & $11(36.7)$ & $13(41.9)$ & $9(30.0)$ & $48(37.8)$ \\
\hline \multicolumn{6}{|l|}{ Age, years } \\
\hline$<65$ & $28(77.8)$ & $29(96.7)$ & $29(93.5)$ & $26(86.7)$ & $112(88.2)$ \\
\hline$\geq 65$ & $8(22.2)$ & $1(3.3)$ & $2(6.5)$ & $4(13.3)$ & $15(11.8)$ \\
\hline Mean (SD) & $46.1(17.7)$ & $39.1(13.6)$ & $43.5(15.6)$ & $46.7(13.8)$ & $43.9(15.5)$ \\
\hline \multicolumn{6}{|l|}{ ASA Class } \\
\hline 1 & $15(41.7)$ & $16(53.3)$ & $17(54.8)$ & $17(56.7)$ & $65(51.2)$ \\
\hline 2 & $13(36.1)$ & $13(43.3)$ & $10(32.3)$ & $11(36.7)$ & $47(37.0)$ \\
\hline 3 & $2(5.6)$ & $1(3.3)$ & $3(9.7)$ & $2(6.7)$ & $8(6.3)$ \\
\hline Unknown & $6(16.7)$ & $0(0.0)$ & $1(3.2)$ & $0(0.0)$ & $7(5.5)$ \\
\hline \multicolumn{6}{|l|}{ BMI, $\mathrm{kg} / \mathrm{m}$} \\
\hline Subjects with data, $n$ & 34 & 30 & 31 & 30 & 125 \\
\hline Mean (SD) & $25.9(2.9)$ & $27.5(4.0)$ & $27.1(3.7)$ & $28.7(2.7)$ & $27.2(3.4)$ \\
\hline
\end{tabular}

$A S A$ American Society of Anesthesiologists, BMI body mass index, NMB neuromuscular blockade 


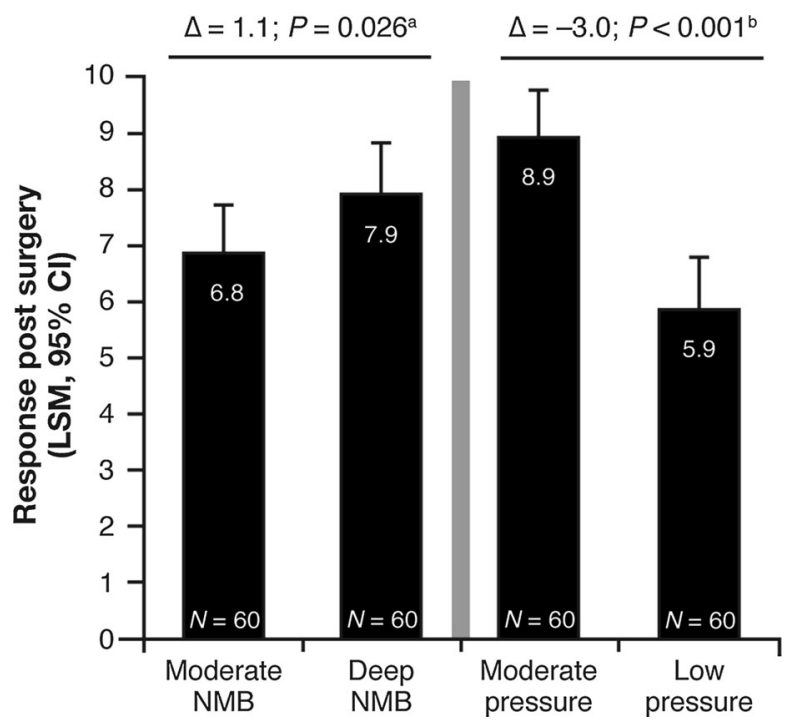

Fig. 2 Surgeon's assessment of overall satisfaction with surgical conditions during surgery (estimates from ANCOVA; full analysis set $)^{\mathrm{a}}$. $\Delta$ difference, $L S M$ leastsquares means, $N M B$ neuromuscular blockade. ${ }^{a}$ Statistically significant $(P<0.05)$. ${ }^{\mathrm{b}}$ Nominally significant (exploratory objective, unadjusted $P<0.05$ )

pre-specified non-parametric analysis was performed due to evidence that the residuals of the ANCOVA model of the primary endpoint were non-normally distributed with non-homogeneous variance. This supportive analysis resulted in a $P$ value of 0.321 for deep versus moderate NMB and $P<0.001$ for low versus standard pressure. Surgical conditions assessments are shown in Table 3.

Another sensitivity analysis, adjusting for the estimated interaction between depth of $\mathrm{NMB}$ and insufflation pressure, showed nearly identical results as the primary approach for deep versus moderate NMB by 1.07 points $(0.12-2.02) ; P=0.028$. Results of this analysis thus supported the primary result demonstrating the effect of deep versus moderate NMB.

The difference in overall average pain score in the first $24 \mathrm{~h}$ after surgery was not statistically significant for either low versus standard pressure or for deep versus moderate NMB (Fig. 3). No significant differences in shoulder pain were observed between the groups. Results for the key secondary analysis were supported by results of the sensitivity analyses by 0.3 points (95\% CI -0.2 to $+0.8 ; P=0.223)$ for deep versus moderate NMB and 0.2 points $(95 \% \mathrm{CI}-0.4$ to $+0.7 ; P=0.565)$ for standard versus low pressure. There was no significant departure from normality or homogeneity of variance for the residuals of the ANCOVA model for the pain scores.

\section{Safety}

There were similar incidences of AEs between the four treatment groups. The majority of the AEs were of mild severity, and none were considered drug-related. The most frequently recorded $\mathrm{AE}$ was pain (88\%), followed by nausea (21\%), vomiting (13\%), pyrexia (13\%), and wound hemorrhage (9\%) (Supplementary Table 1). Six serious AEs were reported for four patients: procedural pain and procedural hemorrhage in one subject each, wound hemorrhage and hematoma in one subject, and necrotizing fasciitis and sepsis in one subject. None were considered related to study medication.

\section{DISCUSSION}

This study confirmed the primary hypothesis that use of deep NMB has an advantage over moderate NMB in improving surgeon satisfaction with surgical conditions in laparoscopic cholecystectomy. A greater degree of muscle relaxation afforded by deep levels of NMB provides improved visibility for the surgeon and fewer involuntary patient movements [9].

In the current study, maintenance of deep NMB throughout surgery was not shown to allow use of lower insufflation pressures without compromising acceptable surgical conditions. Higher levels of intra-abdominal pressure provide increased elevation of the anterior abdominal wall and thus more space for surgical dissection and an enhanced visual field [4]. While not a pre-specified comparison, the results also suggest the possibility of a larger role for insufflation pressure on surgical conditions compared with that of depth of blockade. For instance, no patient in the standard pressure groups required rescue intervention in the present study, whereas a total of 12 patients in the 
Table 2 Surgeon's assessment of overall satisfaction with surgical conditions (full analysis set)

\begin{tabular}{|c|c|c|c|c|}
\hline$\overline{n(\%)}$ & $\begin{array}{l}\text { Moderate } \\
\text { NMB }+ \text { moderate } \\
\text { pressure } \\
(n=31)\end{array}$ & $\begin{array}{l}\text { Moderate } \\
\text { NMB + low } \\
\text { pressure } \\
(n=30)\end{array}$ & $\begin{array}{l}\text { Deep } \\
\text { NMB + moderate } \\
\text { pressure }(n=31)\end{array}$ & $\begin{array}{l}\text { Deep } \\
\text { NMB + low } \\
\text { pressure }(n=30)\end{array}$ \\
\hline \multicolumn{5}{|l|}{ Score ${ }^{a}$} \\
\hline 0 & $0(0.0)$ & $8(26.7)$ & $0(0.0)$ & $5(16.7)$ \\
\hline 2 & $0(0.0)$ & $2(6.7)$ & $0(0.0)$ & $0(0.0)$ \\
\hline 3 & $1(3.3)$ & $1(3.3)$ & $0(0.0)$ & $0(0.0)$ \\
\hline 4 & $0(0.0)$ & $2(6.7)$ & $0(0.0)$ & $1(3.3)$ \\
\hline 5 & $0(0.0)$ & $0(0.0)$ & $0(0.0)$ & $3(10.0)$ \\
\hline 6 & $1(3.3)$ & $2(6.7)$ & $2(6.7)$ & $1(3.3)$ \\
\hline 7 & $1(3.3)$ & $4(13.3)$ & $1(3.3)$ & $2(6.7)$ \\
\hline 8 & $5(16.7)$ & $3(10.0)$ & $5(16.7)$ & $6(20.0)$ \\
\hline 9 & $5(16.7)$ & $2(6.7)$ & $6(20.0)$ & $4(13.3)$ \\
\hline 10 & $17(56.7)$ & $6(20.0)$ & $16(53.3)$ & $8(26.7)$ \\
\hline Missing ${ }^{\mathrm{b}}$ & 1 & 0 & 1 & 0 \\
\hline Mean (SD) & $9.03(1.56)$ & $5.23(3.94)$ & $9.10(1.21)$ & $6.77(3.52)$ \\
\hline LSM (95\% CI) & $8.65(7.58,9.72)$ & $4.99(3.88,6.11)$ & $9.09(8.02,10.17)$ & $6.69(5.57,7.80)$ \\
\hline \multicolumn{3}{|c|}{ Estimated difference } & \multicolumn{2}{|c|}{ Difference in LSM (95\% CI) } \\
\hline \multicolumn{3}{|c|}{ Moderate $\mathrm{NMB}+$ moderate pressure vs moderate $\mathrm{NMB}+$ low pressur } & \multicolumn{2}{|c|}{$3.66(2.30-5.02)$} \\
\hline \multicolumn{3}{|c|}{ Moderate $\mathrm{NMB}+$ moderate pressure vs deep $\mathrm{NMB}+$ moderate pressure } & \multicolumn{2}{|c|}{$-0.44(-1.80$ to +0.91$)$} \\
\hline \multicolumn{3}{|c|}{ Moderate NMB + moderate pressure vs deep NMB + low pressure } & \multicolumn{2}{|c|}{$1.96(0.57-3.36)$} \\
\hline \multicolumn{3}{|c|}{ Moderate $\mathrm{NMB}+$ low pressure vs deep NMB + moderate pressure } & \multicolumn{2}{|c|}{$-4.10(-5.42$ to -2.78$)$} \\
\hline \multicolumn{3}{|c|}{ Moderate NMB + low pressure vs deep NMB + low pressure } & \multicolumn{2}{|c|}{$-1.70(-3.01$ to -0.38$)$} \\
\hline \multicolumn{3}{|c|}{ Deep NMB + moderate pressure vs deep NMB + low pressure } & \multicolumn{2}{|c|}{$2.41(1.08-3.74)$} \\
\hline
\end{tabular}

$L S M$ least-squares mean, $N M B$ neuromuscular blockade

${ }^{a}$ A score of 0 was used for patients with a rescue change in level of NMB or pressure

${ }^{b}$ Not included in summary statistics for score

low pressure groups (7 in the moderate NMB group and 5 in the deep NMB group) underwent rescue intervention via increase in insufflation pressure and/or level of NMB due to surgical conditions which were deemed unacceptable by the surgeon.

Use of deep NMB and low pressure resulted in an improvement in surgical conditions compared with use of moderate NMB with low pressure (the group with the worst surgical conditions), with 1.7 points (95\% CI 3.0-0.4) (Table 2). In contrast, use of deep NMB and standard pressure resulted in an improvement in surgical conditions compared with use of moderate NMB with low pressure of 4.1 points (95\% CI 5.4-2.8) (Table 2). Use of deep NMB with low pressure was found to provide less benefit on conditions than moderate NMB with 
Table 3 Surgeon's surgical conditions assessments (full analysis set)

\begin{tabular}{|c|c|c|c|c|c|c|}
\hline & \multicolumn{4}{|c|}{ Assessment score after surgery } & \multirow{2}{*}{\multicolumn{2}{|c|}{$\begin{array}{l}\text { Pairwise comparison } \\
\text { Deep versus moderate NMB }\end{array}$}} \\
\hline & \multicolumn{2}{|c|}{ Moderate NMB } & \multicolumn{2}{|c|}{ Deep NMB } & & \\
\hline & $\bar{n}$ & LSM & $\bar{n}$ & LSM $(95 \% \mathrm{CI})^{\mathrm{a}}$ & Difference in LSM $(95 \% \mathrm{CI})$ & $P$ value \\
\hline Surgical conditions & 60 & 6.8 & 60 & 7.9 & $1.1(0.1-2.0)$ & 0.026 \\
\hline Visual field & 60 & 6.9 & 60 & 7.8 & $0.9(-0.1$ to -1.9$)$ & 0.063 \\
\hline Muscle relaxation adequacy & 60 & 8.1 & 60 & 8.9 & $0.8(0.3-1.4)$ & 0.004 \\
\hline Insufflation pressure adequacy & 60 & 6.7 & 60 & 7.9 & $1.1(0.3-1.9)$ & 0.006 \\
\hline Number of movements interfering & 60 & 0.9 & 59 & 0.3 & $-0.6(-1.3$ to +0.1$)$ & 0.073 \\
\hline Disruption of surgical performance & 60 & 9.2 & 60 & 9.9 & $0.7(0.2-1.3)$ & 0.009 \\
\hline
\end{tabular}

$L S M$ least-squares mean, $N M B$ neuromuscular blockade

a Based on an analysis of covariance model with factors for depth of NMB (two levels: deep, moderate), level of pressure (two levels: low, standard), body mass index and surgeon

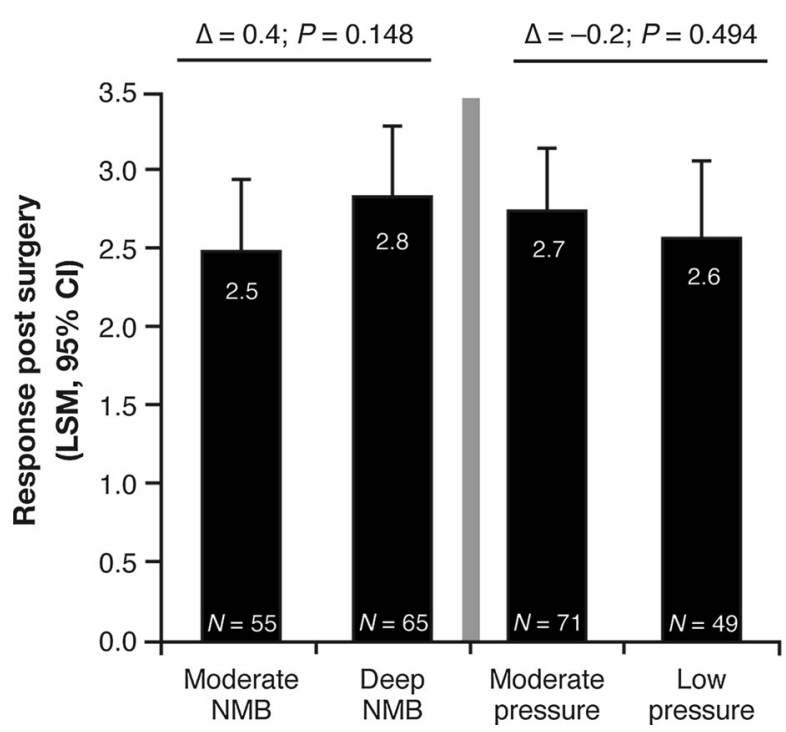

Fig. 3 Average pain score in the first $24 \mathrm{~h}$ after sugammadex administration (estimates from ANCOVA; all-patients-as-treated set). LSM least-squares means, NMB neuromuscular blockade

standard pressure with 2.0 points (95\% CI 0.5-3.4) (Table 2). Therefore, the results from the present study indicate that deep NMB does not replace the need for use of appropriate insufflation pressure with respect to surgical conditions.
The incidence of shoulder tip pain following laparoscopic cholecystectomy is approximately $30-50 \%$ in the literature $[10,11]$. Prior to the design of this study, a Cochrane review [5] concluded that low insufflation pressures were associated with lower post-operative pain scores. This in part formed the hypothesis of the current study that low insufflation pressure combined with deep NMB would result in a lower incidence of patient post-operative pain. However, no significant differences in shoulder pain were observed between the groups in the present study.

The etiology of post-operative pain is complex, although diaphragmatic irritation is generally considered the likely causative factor of post-operative shoulder tip pain, whether by conversion of $\mathrm{CO}_{2}$ to carbonic acid [12] or overstretching of the diaphragmatic muscle fibers [13]. However, stretched pain receptors in the peritoneum can occur both due to high rates of insufflation and as a result of the surgical procedure itself. In addition, the standardized post-operative pain regimen established for this protocol may have masked possible differences in post-operative pain levels between the two groups, contributing to the lack of observed effect.

Of note, during the conduct of the present study, the Cochrane report was revised, 
suggesting insufficient evidence for lower pain levels using low pressure pneumoperitoneum, which is in line with our findings in this study [6]. Therefore, it remains a challenge to investigate pain protection while still maintaining adequate surgical conditions.

This was a pilot study which aimed to investigate the potential for a two-fold benefit for surgeons and patients via use of a combination of deep NMB and low insufflation pressure for endoscopic surgery. Laparoscopic cholecystectomy was chosen for this exploratory study as it is a frequently performed procedure; however, it cannot be ruled out that the greater effects observed with insufflation pressure compared with NMB are at least in part due to the insufflation pressures chosen for investigation. Retrospectively, $8 \mathrm{mmHg}$ may have been too low a pressure to use in a standard surgical population and assessment of a greater range of insufflation pressures may be needed to confirm the benefit of deep neuromuscular block for surgical conditions.

\section{CONCLUSION}

This study demonstrated that the use of sustained deep NMB improves surgical conditions when a low insufflation pressure was applied. However, deep NMB alone cannot adequately replace standard insufflation pressure with respect to surgical conditions. Further studies utilizing a greater range of insufflation pressures may be warranted to ascertain any potential benefits of a lower pressure with respect to surgical conditions. The level of insufflation pressure did not influence the average pain scores measured during $24 \mathrm{~h}$ post-surgery.

\section{ACKNOWLEDGEMENTS}

Sponsorship, article processing charges and the open access fee for this study was funded by was provided by Merck Sharp and Dohme Corp., a subsidiary of Merck \& Co., Inc., Kenilworth, NJ, USA.

Medical writing assistance was provided by Melanie More, of Prime (Knutsford, UK); this assistance was funded by Merck Sharp and Dohme Corp., a subsidiary of Merck \& Co., Inc., Merck, Kenilworth, NJ, USA.

The overall design and conduct of the study, data and opinions, conclusions and interpretation of the data, are the responsibility of the authors. All named authors meet the International Committee of Medical Journal Editors (ICMJE) criteria for authorship for this manuscript, take responsibility for the integrity of the work as a whole, and have given final approval for the version to be published.

List of investigators: Walter Klimscha, MD (Donauspital, Viienna, Austria); Harald J Sparr, MD (Krankenhaus Dornbirn, Dornbirn, Austria); Aki Lumme, MD (Valkeakosken aluesairaala, Valkeakoski, Finland); Hannu Kokki, MD (Kuopion Yliopistollinen Sairaala, Kuopio, Finland); Friedrich Puehringer, MD, PhD (Academic Hospital of the University of Tuebingen, Reutlingen, Germany); Urs Bergner, MD (Kreiskliniken Reutlingen $\mathrm{GmbH}$, Bad Urach, Germany); Michael Moellmann, MD, PhD (St. Franziskus-Hospital, Muenster, Germany); Hinnerk Wulf, MD, PhD (University Hospital Marburg, Marburg, Germany); Alexander Reich (Josephs Hospital, Warendorf, Germany); Carlo Ori, MD (Institute of Anesthesiology and Intensive Care, University Hospital of Padova, Padova, Italy); Martin Shields, MBBCh, BAO (Royal Victoria Hospital, Belfast, UK).

Jacob Rosenberg, Manfred Blobner, Hein Fennema, Peter Grobara, Jan Mulier, Niels Rahe-Meyer, Michael Li, W Joseph Herring, Armin Szegedi and Tiffany Woo were involved in the design of the study and in interpretation of the data. Christopher Assaid was involved in the interpretation of the data. All authors made critical revisions to the manuscript and approved the final version for submission.

Data from this study were presented as a poster at the Annual meeting of the American Society of Anesthesiologists, October 24-28, 2015, San Diego, California.

Disclosures. Jan Mulier has been involved in consultant activity for MSD and has received speaker's honoraria from MSD. Jacob Rosenberg has received speaker's honoraria from Merck. Neils Rahe-Meyer has received speaker's 
honoraria and board membership from Merck. Manfred Blobner has been involved in consultant activity and received speaker's honoraria from Merck. W Joseph Herring is an employee of Merck, Kenilworth, NJ, USA, whom may own stock options in the company. Tiffany Woo is an employee of Merck, Kenilworth, NJ, USA, whom may own stock options in the company. Christopher Assaid is an employee of Merck, Kenilworth, NJ, USA, whom may own stock options in the company. Armin Szegedi is a stock holder and former employee of Merck, Kenilworth, NJ, USA (current affiliation: Allergan, Jersey City, NJ, USA). Michael Li is a former employee of Merck, Kenilworth, NJ, USA (current affiliation: Janssen Pharmaceuticals). Peter Grobara is a former employee of MSD, Oss, The Netherlands. Hein Fennema is a former employee of MSD, Oss, The Netherlands.

Compliance with Ethics Guidelines. The study was conducted in accordance with principles of Good Clinical Practice and with the Helsinki Declaration of 1964, as revised in 2013, and was approved by the appropriate institutional review board/ethics committees. Informed consent was obtained from all patients for being included in the study. The study is reported according to the CONSORT statement.

Data Availability. Merck \& Co., Inc.'s data sharing policy, including restrictions, is available at http://engagezone.merck.com/ds documentation.php. Requests for access to the study data can be submitted through the EngageZone site or via email to dataaccess@merck.com.

Open Access. This article is distributed under the terms of the Creative Commons Attribution-NonCommercial 4.0 International License (http://creativecommons.org/licenses/ by-nc/4.0/), which permits any noncommercial use, distribution, and reproduction in any medium, provided you give appropriate credit to the original author(s) and the source, provide a link to the Creative Commons license, and indicate if changes were made.

\section{REFERENCES}

1. Perrin M, Fletcher A. Laparoscopic abdominal surgery. Contin Educ Anaesth Crit Care Pain. 2004;4:107-10.

2. Lindgren L, Koivusalo AM, Kellokumpu I. Conventional pneumoperitoneum compared with abdominal wall lift for laparoscopic cholecystectomy. Br J Anaesth. 1995;75:567-72.

3. Blobner M, Bogdanski R, Kochs E, et al. Effects of intraabdominally insufflated carbon dioxide and elevated intraabdominal pressure on splanchnic circulation: an experimental study in pigs. Anesthesiology. 1998;89:475-82.

4. Joshipura VP, Haribhakti SP, Patel NR, et al. A prospective randomized, controlled study comparing low pressure versus high pressure pneumoperitoneum during laparoscopic cholecystectomy. Surg Laparosc Endosc Percutan Tech. 2009;19:234-40.

5. Gurusamy KS, Samraj K, Davidson BR. Low pressure versus standard pressure pneumoperitoneum in laparoscopic cholecystectomy. Cochrane Database Syst Rev. 2009;(2):CD006930.

6. Sarli L, Costi R, Sansebastiano G, Trivelli M, Roncoroni L. Prospective randomized trial of low-pressure pneumoperitoneum for reduction of shoulder-tip pain following laparoscopy. Br J Surg. 2000;87:1161-5.

7. Gurusamy KS, Vaughan J, Davidson BR. Low pressure versus standard pressure pneumoperitoneum in laparoscopic cholecystectomy. Cochrane Database Syst Rev. 2014;(3):CD006930.

8. Dubois PE, Putz L, Jamart J, et al. Deep neuromuscular block improves surgical conditions during laparoscopic hysterectomy: a randomised controlled trial. Eur J Anaesthesiol. 2014;31:430-6.

9. Blobner M, Frick CG, Stauble RB, et al. Neuromuscular blockade improves surgical conditions (NISCO). Surg Endosc. 2015;29:627-36.

10. Cunniffe MG, McAnena OJ, Dar MA, Calleary J, Flynn N. A prospective randomized trial of intraoperative bupivacaine irrigation for management of shoulder-tip pain following laparoscopy. Am J Surg. 1998;176:258-61.

11. Tsimoyiannis EC, Glantzounis G, Lekkas ET, et al. Intraperitoneal normal saline and bupivacaine infusion for reduction of postoperative pain after laparoscopic cholecystectomy. Surg Laparosc Endosc. 1998;8:416-20. 
12. Aitola P, Airo I, Kaukinen S, Ylitalo P. Comparison of $\mathrm{N} 2 \mathrm{O}$ and $\mathrm{CO} 2$ pneumoperitoneums during laparoscopic cholecystectomy with special reference to postoperative pain. Surg Laparosc Endosc. 1998;8:140-4.
13. Wallace DH, Serpell MG, Baxter JN, O'Dwyer PJ. Randomized trial of different insufflation pressures for laparoscopic cholecystectomy. $\mathrm{Br} \mathrm{J}$ Surg. 1997;84:455-8. 